\title{
THE ANATOMY OF THE LAMINA TERMINALIS AND CISTERNA CHIASMATICA: A CADAVERIC STUDY AT THE UNIVERSITY TEACHING HOSPITAL, LUSAKA, ZAMBIA
}

\author{
Vivienne Nambule Syamuleya ${ }^{1}$, Isaac Sing'ombe ${ }^{1}$, Fridah Mutalife ${ }^{1}$, Sikhanyiso Mutemwa ${ }^{1}$, Elliot \\ Kafumukache $^{1}$, Krikor Erzingatsian ${ }^{2}$
}

1. Department of Anatomy, School Of Medicine, University of Zambia Lusaka, Zambia.

2. Department of Surgery and Anatomy, School of Medicine, University of Zambia, Lusaka, Zambia

Correspondence to Mrs.Vivienne Nambule Syamuleya. Email: viviennenambule@gmail.com

\begin{abstract}
The Lamina Terminalis represents an important neuroanatomical structure by which third Ventriculostomy could be performed into the subarachnoid space through the Cisterna Chiasmatica. Recent studies have indicated a role for Lamina Terminalis fenestration in approaching pathologies of the third ventricle. However, there is limited knowledge on the anatomical features, variations and the vasculature of the Lamina Terminalis in a Zambian population. This study was aimed to explore the anatomy of the Lamina Terminalis, the Cisterna Chiasmatica and its neurovascular relationships as seen in a Zambian population and compare with the findings in the literature. The study was a descriptive cross-sectional design in which 32 post-mortem human cadaveric brains were systematically sampled. The Lamina Terminalis region was examined in 27 male cadavers and five female cadavers of age range between 25 and 66 years (mean $34.1 \pm 9.2$ years). Data was collected using a data collection form, entered and analyzed by descriptive statistics using Statistical Package for Social Sciences (SPSS) software version 22. Mean and standard deviations were used to describe variables. The base of the brain was detached from the floor of the cranial cavity and the Lamina Terminalis exposed fully by retracting both optic nerves and the optic Chiasma posteroinferiorly. The triangular Lamina Terminalis measurements were performed as the distance between the midportion of the upper aspect of the chiasma and the lower aspect of the anterior commissure (height), which averaged $8.6 \pm 1.0 \mathrm{~mm}$. The distance between the medial edges of the optic tracts (base) averaged $13.1 \pm 1.1 \mathrm{~mm}$ and the area averaged $56.9 \pm 11.6 \mathrm{~mm} 2$. The Lamina Terminalis membrane showed variations in appearance; 20 were transparent with a large dark midline gap and 10 were less translucent with a slender midline gap and two were indistinct. The Cisterna Chiasmatica was observed as a dilated subarachnoid space adjacent to the Optic Chiasma. For neurovascular relationships, 24 cadavers showed arterioles arising from the posterosuperior aspect of the anterior cerebral artery to perforate the anterior perforating substance(s), supplying the chiasma, and optic tracts; whereas, eight cadavers showed arterioles arising posteroinferiorly and ramifying on the Lamina Terminalis. The Lamina Terminalis membrane is variably developed. There are variations in the membrane appearance, measurements and neurovascular relationships. These findings will supplement a knowledge gap in neuroanatomy and help prevent complications during Lamina Terminalis fenestration in approaching pathologies of the third ventricle.
\end{abstract}

Key words: Lamina Terminalis, Cisterna Chiasmatica, Third Ventriculostomy

\section{INTRODUCTION}

The Lamina Terminalis represents an important neuro-anatomical structure by which to fenestrate the third ventricle into the subarachnoid space through the Cisterna
Chiasmatica (Tubbs 2012). The Cisterna Chiasmatica is a dilatation of the subarachnoid space which lies adjacent to the Optic Chiasma and filled with freely circulating cerebral spinal 
fluid (Siegel 2006). Rhoton (1987) described the Lamina Terminalis as a triangular, transparent whitish membrane found at the base of the brain and forms the anterior wall of the third ventricle. It attaches to the upper surface of the Chiasma and stretches upward to fill the interval between the optic Chiasma and the corpus callosum (Retzius G, 1896). The Lamina Terminalis and the Optic Chiasma (OC) form part of the anterior wall of the third ventricle visible on the surface, and when viewed from within, the boundaries of the anterior wall from superiorly to inferiorly are formed by the Lamina Terminalis together with columns of the fornix, foramen of monro, anterior commissure, optic recess, and optic Chiasma (Rhoton 1987). Lamina terminalis opening would permit adequate flow of excess Cerebral Spinal Fluid (CSF) into the subarachnoid space (Tubbs 2012) and this could help manage pathologies of the third ventricles such as hydrocephalus which is one of the commonest neurosurgical conditions in children (Ryan et al., 2016). In Zambia; Sub Saharan Africa; and Africa as a whole, has no adequate documentation and literature on the anatomy of the lamina terminalis and its possible variations. The anatomy of the Lamina Terminalis has not been extensively described. These findings will supplement a knowledge gap in neuroanatomy and help prevent complications during Lamina Terminalis fenestration in approaching pathologies of the third ventricle.

\section{MATERIALS AND METHODS}

This was a descriptive cross-sectional design in which thirty-two adult post-mortem human cadaveric brains were systematically sampled at the University Teaching Hospital Pathology Department, Lusaka Zambia. The Lamina Terminalis region located at the base of the brain was dissected and examined in 27 male cadavers and five female cadavers of age range 25 and 66 years (mean $34.1 \pm 9.2$ years). Data was collected using a data collection form. It was tabulated and analyzed by descriptive statistics using Statistical Package for Social Sciences (SPSS) software version 22. Mean and standard deviations were used to describe variables. The base of the brain was detached from the floor of the cranial cavity and the Lamina Terminalis was exposed fully by retracting both optic nerves and the optic Chiasma posteroinferiorly. The Lamina Terminalis region was examined in 32 adult cadavers. The anatomical features of the Lamina Terminalis and Cisterna Chiasmatica were observed and noted. The shape and dimensions of the Lamina Terminalis area were measured using a Digital Vernier Caliper. The Cisterna Chiasmatica a dilated subarachnoid space was examined in particular with neurovascular structures adjacent to the Lamina Terminalis. A Head held magnifying glass/loop was used to magnify minute structures.

\section{RESULTS}

This study shows that the majority twentyseven $(84.4 \%)$ were male compared to five $(15.6 \%)$ female cases and the reason being that during the time of study the frequency of male cases undergoing autopsy was higher compared to female cases. However, no differences in the anatomy and measurements of the Lamina Terminalis between males and females were noted in this study statistically.
The age in this study ranged from twenty-five - sixty-six years (mean $34.1 \pm 9.2$ years). It is stated that although brain development is subject to significant individual variation, most experts suggest that the brain is fully developed by age twenty-five years (https://mentalhealthdaily.com>2015/02/18). This study was conducted at an age when the question of age effecting Lamina Terminalis dimensions does not arise. In the study conducted by de Divitiis (2002), the author also 
chose this age range; equally Castilla (2012) in his study used the mean age of 28 years. They did not take into consideration the effect of

Table 1: Demographic Characteristics $(n=32)$

(a) Gender

\begin{tabular}{|l|l|l|l|l|}
\hline Characteristics & Frequency & Percentage & Valid Percent & $\begin{array}{l}\text { Cumulative } \\
\text { Percent }\end{array}$ \\
\hline Male & 27 & 84.4 & 84.4 & 84.4 \\
\hline Female & 5 & 15.6 & 15.6 & 100 \\
\hline Total & 32 & 100 & 100 & \\
\hline
\end{tabular}

Table 3(a): Shows majority were male twenty-seven (84.4\%) and five (15.6\%) were female.

\section{(b) Age}

\begin{tabular}{|l|l|l|l|l|l|}
\hline Characteristic & Number & Minimum & Maximum & Mean & $\begin{array}{l}\text { St. } \\
\text { Deviation }\end{array}$ \\
\hline Age & 32 & 25 & 66 & 34.1 & 9.2 \\
\hline
\end{tabular}

Table 3(b) shows that the age ranged from twenty five - sixty six years (mean $34.1 \pm 9.2$ years).

Table 1: Shape and Appearance of the Lamina Terminalis and Cisterna Chiasmatica

\begin{tabular}{|l|l|l|l|l|}
\hline Characteristics & Frequency & Percent & Valid Percent & Cumulative Percent \\
\hline Triangular shape & 32 & 100 & 100 & 100 \\
\hline Appearance & & & & \\
-Transparent & 20 & 62.5 & 62.5 & 62.5 \\
-Translucent & 10 & 31.3 & 31.3 & 93.8 \\
-Indistinct & 2 & 6.3 & 6.3 & 100 \\
\hline $\begin{array}{l}\text { CC- observed as dilated } \\
\text { subarachnoid space }\end{array}$ & 32 & 100 & 100 & \\
\hline
\end{tabular}

The Lamina Terminalis was found to be a triangular shaped membrane which varied in appearance. Twenty (62.5\%) appeared transparent while ten $(31.3 \%)$ appeared translucent and two (6.3\%) appeared

indistinct. The Cisterna Chiasmatica was observed as a dilated subarachnoid space extending forward anterosuperior to the optic chiasma.
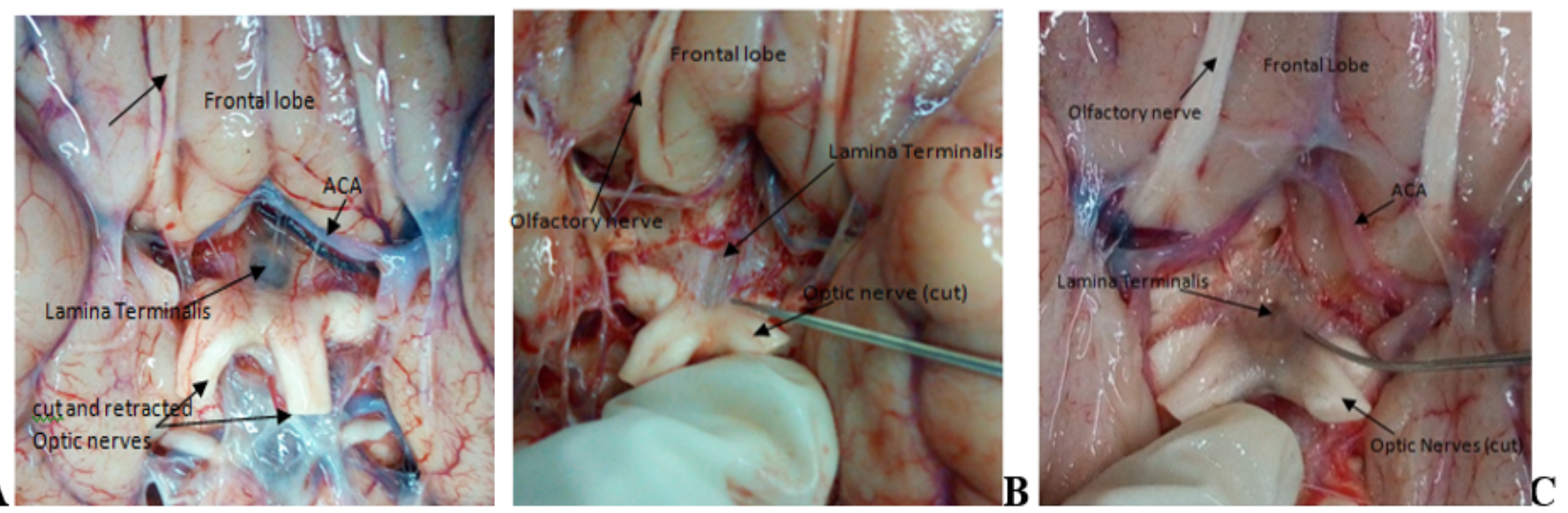

Figure 1: Variations of the Lamina Terminalis. Picture $(A)$ large and transparent, $(B)$ less transparent and reduced to a 
slender midline gap, (C) less distinct and less transparent. Optic nerves were cut and retracted to expose the Lamina Terminalis fully.

Table 2: Height, Base and Area of the Lamina Terminalis $(\mathbf{n}=32)$

\begin{tabular}{|l|l|l|l|l|l|}
\hline Measurements & $\begin{array}{l}\text { Numbe } \\
\mathbf{r}\end{array}$ & Minimum & Maximum & Mean & Std.Deviation \\
\hline Height of LT $(\mathrm{mm})$ & 32 & 7.8 & 12.2 & 8.6 & 1.0 \\
\hline Base of LT $(\mathrm{mm})$ & 32 & 11.1 & 16.3 & 13.1 & 1.1 \\
\hline Area of LT $\left(\mathrm{mm}^{2}\right)$ & 32 & 43.3 & 99.4 & 56.9 & 11.6 \\
\hline
\end{tabular}

The triangular shaped Lamina Terminalis measured Height on average 7.8 - $12.2 \mathrm{~mm}$ (mean 8.6 $\pm 1.0 \mathrm{~mm}$ ) whilst the Base averaged $11.1-16.3 \mathrm{~mm}$ (mean $13.1 \pm 1.1 \mathrm{~mm}$ ) and the Area averaged 43.3 - $99.4 \mathrm{~mm}^{2}$ (mean $\left.56.9 \pm 11.6 \mathrm{~mm}^{2}\right)$.

Table 3: Relationship between AComA and Lamina Terminalis $(n=32)$

\begin{tabular}{|l|l|l|l|l|l|}
\hline Measurements & Number & Minimum & Maximum & Mean & $\begin{array}{l}\text { Std. } \\
\text { Deviation }\end{array}$ \\
\hline $\begin{array}{l}\text { Distance between AComA } \\
\text { and LT (mm) }\end{array}$ & 32 & 7.8 & 15.0 & 9.8 & 2.0 \\
\hline
\end{tabular}

Distance between the AComA and the Lamina Terminalis ranged from $7.8-15.0 \mathrm{~mm}$ (mean $9.8 \pm$ $2.0 \mathrm{~mm})$

Table 4: Relationship between the Optic Chiasma and Anterior Commissure $(n=32)$

\begin{tabular}{|l|l|l|l|l|l|}
\hline Measurements & Number & Minimum & Maximum & Mean & SD \\
\hline Length from OC to AC & 32 & 7.8 & 12.2 & 8.6 & 0.9 \\
\hline
\end{tabular}

Length between the Optic Chiasma and Anterior Commissure ranged from 7.8 - 12.2mm (mean 8.6 $\pm 0.9 \mathrm{~mm})$.

Table 3: Perforating Vessels from the Anterior Cerebral Artery $(n=32)$

\begin{tabular}{|l|l|l|l|l|}
\hline $\begin{array}{l}\text { Area Perforated by ACA } \\
\text { branches }\end{array}$ & Frequency & Percent & $\begin{array}{l}\text { Valid } \\
\text { Percent }\end{array}$ & $\begin{array}{l}\text { Accumulative } \\
\text { Percent }\end{array}$ \\
\hline Anterior Perforating Substance & 24 & 75 & 75 & 75 \\
\hline LT & 8 & 25 & 25 & 100 \\
\hline Total & 32 & 100 & 100 & \\
\hline
\end{tabular}

Perforators where found perforating the anterior perforating substance(s) in twentyfour $(75 \%)$ while in eight $(25 \%)$ arterioles from the Anterior Cerebral Arteries where found ramifying on the Lamina Terminalis. 


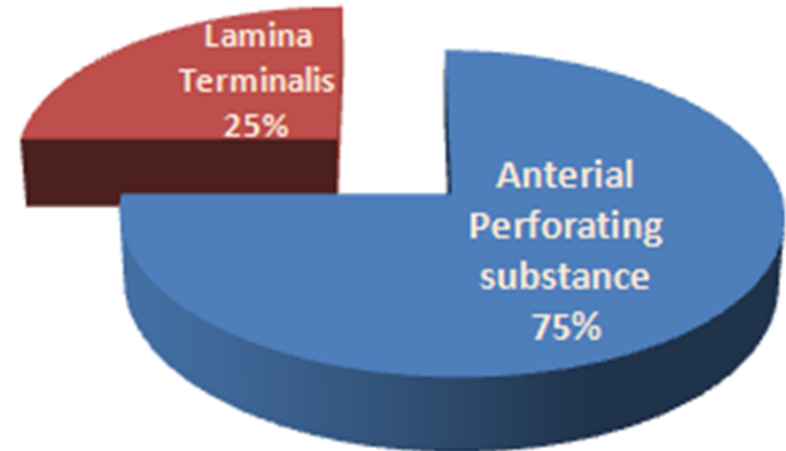

Figure 2: Perforating vessels. Perforating Vessels from the Anterior Cerebral Artery Segment A1

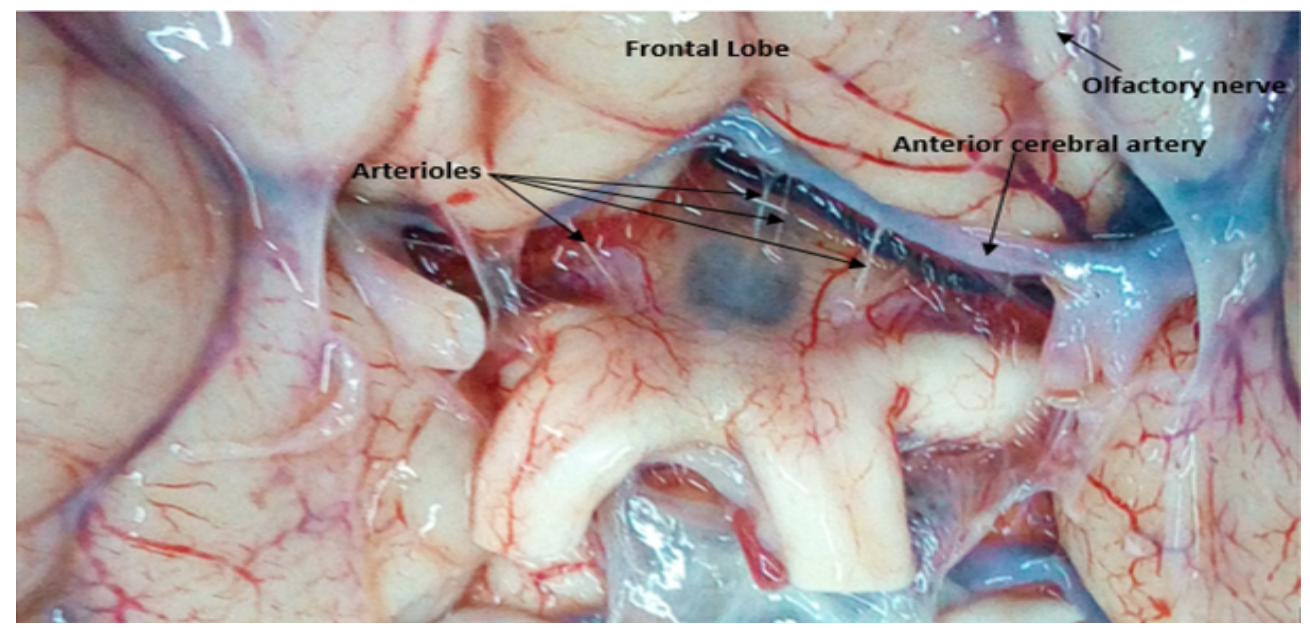

Figure 3: Arterioles from the Anterior Cerebral Artery segment A1 ramifying on the Lamina Terminalis . Small arterioles ramifying on the Lamina Terminalis from the ACA segment A1. Arterioles from the Anterior Cerebral Artery segment A1

\section{DISCUSSION}

The current study has showed the Lamina Terminalis to be a paper-thin triangular membrane of variable appearance. In twenty $(62.5 \%)$ the Lamina Terminalis was found as a transparent membrane while in ten $(31.3 \%)$ it was translucent and in two $(6.3 \%)$ it was indistinct. These results are similar to the studies conducted by Retzius (1896) a century ago and Rhoton (1986). The current study found the Cisterna Chiasmatica as a space extending forward anterosuperior to the optic chiasma similar to other studies in literature.

The Lamina Terminalis measured on average: Height 7.8 - 12.2mm (mean $8.6 \pm 1.0 \mathrm{~mm}$ ), Base $11.1-16.3 \mathrm{~mm}$ (mean $13.1 \pm 1.1 \mathrm{~mm}$ ) and the Area 43.3 - $99.4 \mathrm{~mm} 2$ (mean $56.9 \pm$ $11.6 \mathrm{~mm} 2$ ). The measurements of the Lamina Terminalis in the current study have shown similar ranges with the findings of de Divitiis (2002).
Concerning the neurovascular relationships, the current study found the length between the Optic Chiasma and the Anterior Commissure as ranging from 7.8 - $12.2 \mathrm{~mm}$ (mean 8.6 $\pm 0.9 \mathrm{~mm}$ ) whilst distance between the AComA and the Lamina Terminalis ranged from 7.8$15.0 \mathrm{~mm}$ (mean $9.8 \mathrm{~mm} \pm 2.0 \mathrm{~mm}$ ). The mean range in length from the Optic Chiasma to the Anterior Commissure in the current study and that of de Divitiis (2002) show similar results whilst the mean range in distance between AComA and the Lamina Terminalis showed discrepancies with the current study having a longer distance by $6.3 \mathrm{~mm}$.

The current study found the posterior superior branches in twenty four (75\%) arising from the Anterior Cerebral Arteries Segment A1 to perforate the Anterior Perforating Substance(s) and taking a similar course as in the study by Pai (2005) to supply the optic chiasma, anterior 
commissure, hypothalamus and the internal capsule however, different from other findings the current study showed eight (25\%) arterioles arising from the posterior inferior surface of the Anterior Cerebral Arteries segment $A 1$ to ramify across the Lamina Terminalis. Gomes et al (1986) also found that the perforating branches of the proximal segment of the anterior cerebral artery penetrated the brain at the anterior perforating substance(s), lateral chiasma, and optic tracts. Salaud et al (2018) has also shown blood supply to the Optic Chiasma from the Anterior Cerebral Arteries, Anterior Communicating Artery and hypophyseal arteries. Although there have been many studies of the arterial cerebral blood supply, no literature has adequately focused on the vasculature of the Lamina Terminalis structure.

This finding of the arteriole branches from the Anterior Cerebral Arteries Segment A1 ramifying on the Lamina Terminalis has not been indicated by other studies. Disregarding these small vessels in this area may cause unacceptable morbidity and mortality (Pia 2005) during surgery thus we concur with Retzius that surgical procedures should be confined to the central area of the Lamina Terminalis to avoid such vessels

Table 9: The Lamina Terminalis Morphometry compared with other studies.

\begin{tabular}{|l|l|l|l|l|l|}
\hline Measurements & $\begin{array}{l}\text { Yamamot } \\
\text { o et al } \\
\mathbf{1 9 8 1}\end{array}$ & $\begin{array}{l}\text { Lang } \\
\mathbf{1 9 8 5} \\
\mathbf{1 9 9 2}\end{array}$ & $\begin{array}{l}\text { Serizawa } \\
\text { et al 1997 }\end{array}$ & $\begin{array}{l}\text { de Divitiis } \\
\mathbf{2 0 0 2}\end{array}$ & $\begin{array}{l}\text { Present } \\
\text { Study }\end{array}$ \\
\hline Height (length) of LT mm & $\begin{array}{l}10(8.0- \\
12.0)\end{array}$ & $\begin{array}{l}10.85(5.0 \\
-16.0)\end{array}$ & Not reported & $\begin{array}{l}8.25(7.0- \\
10.0)\end{array}$ & $8.6(7.8-12.2)$ \\
\hline Base of LT mm & $\begin{array}{l}\text { Not } \\
\text { reported }\end{array}$ & $\begin{array}{l}\text { Not } \\
\text { reported }\end{array}$ & Not reported & $\begin{array}{l}12.81(8.0- \\
18.5)\end{array}$ & $\begin{array}{l}13.1(11.1- \\
16.3)\end{array}$ \\
\hline Area of LT mm ${ }^{2}$ & $\begin{array}{l}\text { Not } \\
\text { reported }\end{array}$ & $\begin{array}{l}\text { Not } \\
\text { reported }\end{array}$ & Not reported & $\begin{array}{l}52.84(31.5- \\
83.25)\end{array}$ & $\begin{array}{l}56.9(43.3- \\
99.4)\end{array}$ \\
\hline $\begin{array}{l}\text { A Com A distance to LT } \\
\text { mm }\end{array}$ & $\begin{array}{l}\text { Not } \\
\text { reported }\end{array}$ & $\begin{array}{l}\text { Not } \\
\text { reported }\end{array}$ & $30 \%$ over LT & $3.5(0-14)$ & $9.8(7.8-15.0)$ \\
\hline
\end{tabular}

This table shows the comparison of Previous Descriptions of the Lamina Terminalis and its Neurovascular Relationships with other studies

\begin{tabular}{|c|c|c|}
\hline Measurements & de Divitiis & Present Study \\
\hline Length of $\mathrm{OC}$ to $\mathrm{AC}$ & $8.25(7-10) \mathrm{mm}$ & $8.6(7.8-12.2) \mathrm{mm}$ \\
\hline Area (Base x 1/2 Height) & $52.84(31.5-83.25) \mathrm{mm}^{2}$ & $56.9\left(43.3-99.4 \mathrm{~mm}^{2}\right)$ \\
\hline $\begin{array}{l}\text { Distance between AComA } \\
\text { and LT } \\
\text { - }\end{array}$ & $3.5(0-14) \mathrm{mm}$ & $8.6(7.8-12.2) \mathrm{mm}$ \\
\hline $\begin{array}{l}\text { No. of Perforators } \\
\begin{array}{ll} & \text { from AComA } \\
- & \text { from ACA }\end{array}\end{array}$ & $\begin{array}{l}6 \text { in } 20 \\
6 \\
0\end{array}$ & $\begin{array}{l}8 \text { in } 32 \\
0 \text { in } 32 \\
8 \text { in } 32 \text { (6-both Right and Left } \\
\text { sides } \\
\text { 2-Right side only) }\end{array}$ \\
\hline
\end{tabular}

In conclusion, the Lamina Terminalis membrane is variably developed with variations in the membrane appearance, measurements and neurovascular relationships. These findings will 
supplement a knowledge gap in neuroanatomy and help prevent complications during Lamina Terminalis fenestration in approaching pathologies of the third ventricle.

ACKNOWLEDGEMENTS: My special thanks go to my supervisor, Professor K. Erzingatsian and Cosupervisor Doctor E. Kafumukache for constructive criticisms and guidance, which helped me, shape the project in the right direction. My colleagues, family and friends I say thank you for your encouragement and support. My utmost appreciation goes to my sponsors: The Ministry of Health for the financial support making it possible for me to pursue Masters of Science in Human Anatomy and complete my research project.

\section{REFERENCES}

1. De Divitiis O (2002): Microsurgical Anatomic Features of the Lamina Terminalis. Neurosurgery 50 (3): 563-570

2. Enrico de Divitiis, Andrea Elefante, Oreste de Divitiis (2014): Laterosellar compartment or cavernous sinus? What's the correct term? World Neurosurgery 1-2 (82):e93-e96

3. Garg, A. (2009): Endoscopic Third Ventriculostomy. Pediatric Neurosurgery 45 (1): 1-5

4. Gomes F.B, Dujovny M, Umansky F, Berman S.K, Diaz F.G, Ausman J.I, Michandani H.G, Ray W.J (1986): Microanatomy of the Anterior Cerebral Artery. Surg Neurol.26 (2): 129-41

5. Pai S.B, Kulkarni R.N, Varma R.G Varm (2005): Microsurgical Anatomy of the ACA-

A Com A Complex. Neurology Asia, 10: 21 - 28.

6. Retzius G (1896): Das Menschenhim: Studien in der Makroskopischen Morphologie. Stockholm, Koeniglich Buchdruckerei

7. Rhoton A. L, Jr. (2002): The Sellar region anatomy. Neurosurgery 51 (1) SI-335-SI-374.

8. Ryan T. M, Shelly W, Benjamin C.W (2016): Global surgery for pediatric hydrocephalus in the developing world: a review of the history, challenges, and future directions. Neurosurgical focus, 41: 1

9. Sadler T. W. (2012): Langman's medical embryology, 12th Ed. Philadelphia: Lippincott William \& Wilkins. 303-306Sadler T.W. (2005). Langman's medical embryology, 9th Ed. Philadelphia: Lippincott Williams \& Wilkins. 458

10. Salaud C, Ploteau S, Blery P, Pilet P, Armstrong O, Hamel A (2018): Extrinsic and Intrinsic Blood Supply to the Optic Chiasma. Clinical Anatomy 31: 432-440

11. Sindou M (1994): Favourable influence of opening the lamina terminalis and Lilliequist's membrane on the outcome of ruptured intracranial aneurysms: A study of 197 consecutive cases. Acta Neurochir (Wien) 127:15-1

12. Snell, Richard S. (2010): Clinical Neuroanatomy, 7th Ed. Philadelphia, Pennsylvania. Lippincott Williams \& Wilkins. Chapter 16 - p446, 265

13. Spena, G (2008): Sub frontal endoscopic fenestration of Lamina Terminalis an anatomical study: min- Minimally Invasive Neurosurgery. 51(6) 319 - 323S

14. Tubbs $R$, Nguyen $H$, Loukas $M$, and Cohen-Gadol A (2012): Anatomic study of the lamina terminalis: neurosurgical relevance in approaching lesions within and around the third ventricle. Child's Nervous System 8(28) 1149-1156

15. Tomasello F, d'Avella D, de Divitiis O (1999): Does lamina terminalis fenestration reduce the incidence of chronic hydrocephalus after subarachnoid hemorrhage? Neurosurgery 45:827832, 1999.

16. Tortora G, J and Nielsen M, T (2012): Principles of human anatomy 12th Ed. The United States of America. John Wiley \& Sons, Inc. 643 
Anatomy Journal of Africa. 2019. Vol 8 (1):1452 - 1459

17. Yamamoto I, Rhoton A. L, Peace D (1987): Microsurgery the third ventricle. Neurosurgery 8(3) 334-356

18. Yasargil M.G (1999): Preface, in Chronic Hydrocephalus following Aneurysmal Subarachnoid Hemorrhage. P 5-6. 